\title{
College English Teaching on the Background of MOOCs
}

\author{
Xiuli Qu \\ Teaching and Research Institute of Foreign Languages, Bohai University, Jinzhou, 121013, China \\ lename2008@126.com
}

Keywords: MOOCs; college English teaching; MOOCs resource development; MOOCs resource platform

\begin{abstract}
MOOCs is a new teaching mode in the trend of the Internet. MOOCs is applied for college English teaching, optimize the teaching resources and teaching environment, teaching process and teaching goals, improve the learning efficiency and teaching effect, provide a new perspective for college English teaching reform. In view of the realistic problems in the application for MOOCs, this paper studied the MOOCs for the role of college English teaching and then studied for college English teaching classes of MOOCs resource development and longed for MOOCs resource platform. This article research results is of great significance to promote MOOCs for application in college English teaching, improving the quality of college English teaching and improve students' English comprehensive ability, etc.
\end{abstract}

\section{Introduction}

MOOCs (Massive Open Online Course) is provided by the Canadian scholar Dave Cormier with Bryan Alexander in 2008, in video recording and transmission, with students as the main body in the service, at the same time the public oriented "Massive Open Online courses". As shown in Fig. 1. The first letter " $\mathrm{M}$ " is for Massive, and the traditional courses only dozens or hundreds of students, a course of MOOCs frequently tens of thousands of people, up to hundreds of thousands of people. The second letter "O" is for the Open, in order to interest orientation, who want to learn, can come in, regardless of their nationality, just a mailbox, can register to participate in; The third letter "O" is for the Online, Online learning is complete, do not need to travel, without being limited by the space and time; The fourth letter "C" is for Course, is the meaning of Course. For MOOCs is to increase knowledge dissemination and released by individual organization with sharing and collaborative spirit of the open class, spreading on the Internet, with the traditional network curriculum based on a campus network or local area network (LAN), compared with characteristics of openness, flexibility, large scale, will be moved to the online classroom teaching activities, and truly realize the "flipped classroom" and network resource sharing.

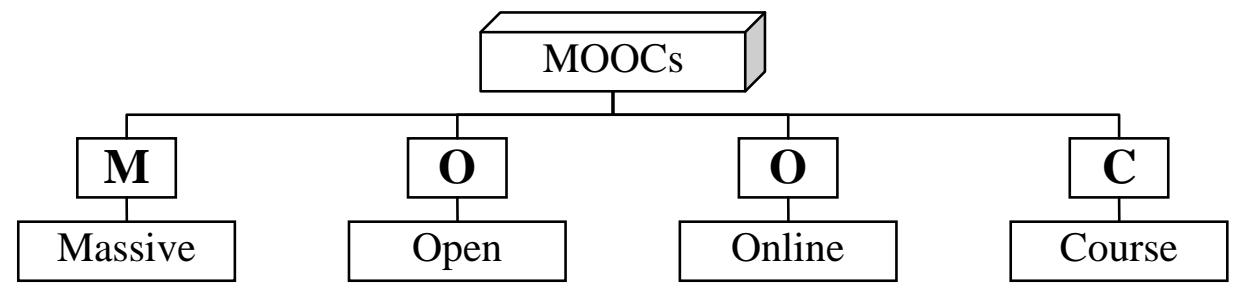

Fig. 1. Flipped classroom teaching mode

College English teaching quality, curriculum content and evaluation approach in China has been questioned all the time. As the wave of MOOCs worldwide, college English teaching encountered unprecedented challenges, but also bring huge opportunities for development. The biggest advantage of MOOC is to make global free sharing school teacher in the name of the course, learners will pace since the study course content; Spare capacity of students to study subjects that they are interested in autonomous learning, finish time homework, participate in the global online community to discuss course content, exchange their learning experience. In general college English is more and more difficult today to students' attention, can according to the needs of MOOCs course appropriate adjust the college English course system. According to the learners 
MOOCs learning situation, adjust teaching content, motivate students to learn English. Through international MOOCs learning, learners can not only test and promote language level, can also enhance professional knowledge or cultural literacy.

\section{MOOCs Applied to College English Teaching}

"MOOCs" education mode is not only a challenge to the traditional college English teaching, but more provides a new Angle of view for college English teaching, become a new fulcrum for college English course teaching reform. MOOCs for the role of college English teaching are as follows [1-9]:

(1) Provides a new way for English "seeing, listen to, saying" teaching. Traditional English teaching mainly explain the text, vocabulary phrases usage and after-school exercises, etc. "To listen to, saying that" class is less, only heard that textbook exercises. The modern " to listen to, saying" course is not enough, the traditional single teaching content boring, preaching, while covering areas such as politics, economy, culture and life, but due to the limitation of the teaching content and the whole class planning, provide students with the chance of cultural background knowledge is too little, most of the teaching contents only stays at the material level, is not an effective way to improve the level of students heard that. Longed for MOOCs under the environment of English "visual, listening, said," is to enrich the cultural knowledge and improve the training of listening skills, and learn to analysis, judgment, reasoning, and strengthen the ability of other comprehensive training process. Teaching task should according to different students follow the principle of moderately interesting, diverse, and the right amount of arrangements, usually can use images combined with audio, text and audio-visual combination, such as spoken language with audio-visual teaching form.

(2) Strengthen the socialization function of the college English education. Socialization refers to the specific social and cultural environment, individuals through social interactions, and develop their own social, be able to fulfill the process of social role behavior of people. Students not only belong to the school, more belong to the society. The student to carry on the reasonable localization, break through the bondage of the corners of the sky on campus students in study and life in social melting pot, let the students healthy growth in the unceasing innovation, the responsibility is each education workers. Longed for MOOCs of college English education against the background of social features include two aspects, one is, the social education in order to develop the students' ability of social belief and knowledge as the goal, through education and training of future adult role to make the students, to prepare for the future to engage in social life; Second, break the restrictions on the walls of college English, extend the education object of college English course, the college English education is everywhere, give full play to its social function.

(3) The role of English teachers' profound changes has taken place. The ultimate purpose of English teaching is to cultivate the students' English communicative competence. The best effect of English teaching is the result of effective cooperation between teachers and students. Under the background of MOOCs, English teachers' education concept, teaching methods and teaching behavior has changed. By authority into the teaching activities of participants, change by the lecturers to learning equal partners, the organizers of the masters into learning qualified, by the knowledge disseminator into learning guidance, into the developer by the owners of education resources, English teachers should change education idea, guide students to actively participate in classroom interaction activities, create a relaxed and happy classroom atmosphere, make students communicate with each other in the interactive activities and incentive, the organic combination of language knowledge and language skills, combine personal experience and language learning, combine language learning and the whole-person education, make students have the English comprehensive ability and creativity talent.

(4) Choose the types of MOOCs for college English teaching. For class according to the teaching service concept can be divided into three categories: cMOOCs build configurations for knowledge, learning theory is based on unicom, emphasis on creation, learning autonomy and social network, learners by establishing a network connection between the knowledge points, to construct 
knowledge and develop ability; XMOOCs for knowledge dissemination, based on behaviorism learning theory, focused on the spread of knowledge and reproduction, learners use of social networking tools to establish learning network, to carry out autonomous learning activities; TMOOCs type for skills, based on the constructivism learning theory, focused on the complex skills, emphasizes the learning community, case and architecture. In this paper, we study the course for college English teaching, the main service object is a college student or social related people to acquire knowledge, thus suitable for xMOOCs type, combination of traditional classroom teaching organization form, make the future extension of mature teaching model in the network space, meet the needs of the students learning mobile access and debris.

(5) Enhance the systemic of college English teaching content. Any knowledge is not an isolated phenomenon, the knowledge of English is also has the characteristics of systemic. Due to the constraints of traditional teaching thought, teaching content, the lack of system science, affecting the student to the knowledge system. English teaching first understanding of the systemic integral structure, as shown in Fig. 2, handle various relations within the system. Through English teaching in listening, speaking, reading and writing, translation and other courses, causes the student to obtain knowledge of English, the few courses need to do thorough and system arrangement, to form an efficient overall. At the same time, the dissemination of knowledge of English teaching process is not isolated, to the restriction of the environmental factors. Regardless of the objective environment, English teaching will not be able to play a proper role. So English teaching system entities in the teaching system and teaching environment are mutually dependent and restraining each other, the interaction between the factors and apply each other formed the basis of English teaching system benign operation. MOOCs for many large data automatically generated in the process of teaching, teachers through huge amounts of data analysis, tracking learners, including each of the learning time and frequency, number and contents of the online questions and discussion, the completion homework, practice tests, analysis for accumulation law of education, improve the teaching contents and methods. Combined with the actual situation of college English lesson for, in the teaching process, reasonable arrangement of courses, pay more attention to the systemic of the students to learn English, Strengthen the teaching management, for the English teaching system to provide a good working environment; Attaches great importance to the role of people, teachers' and students' subjective initiative into full play.

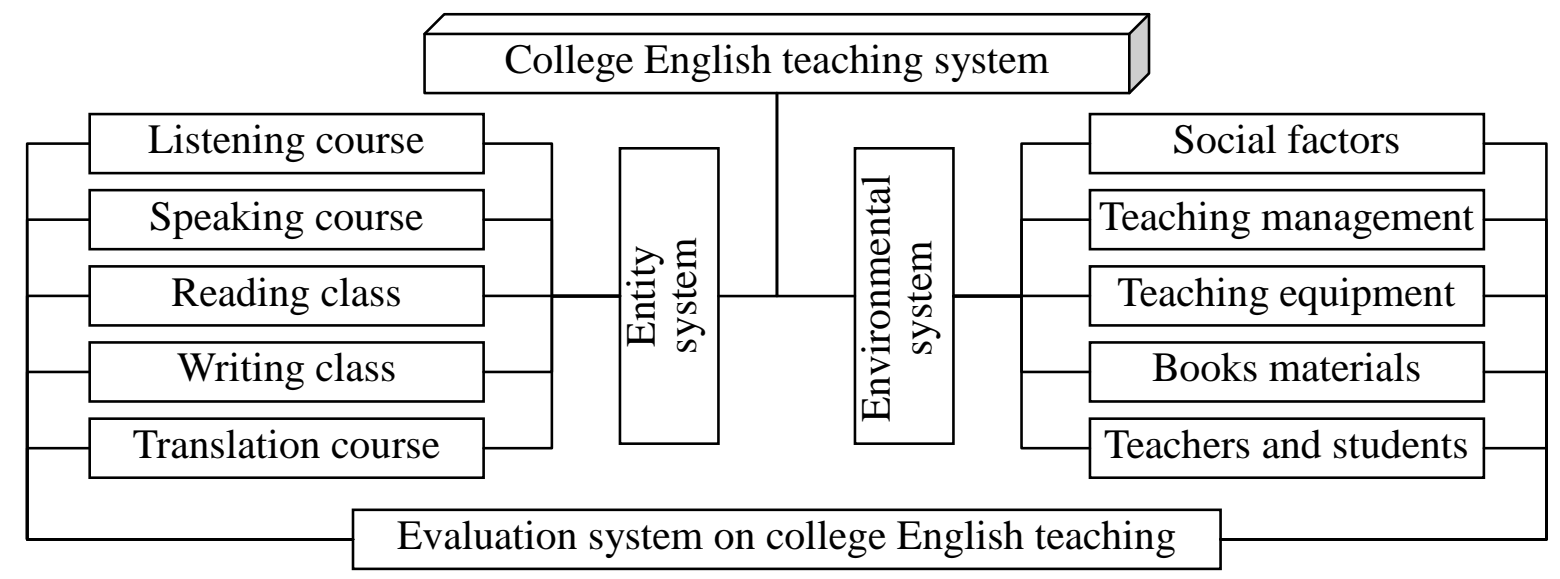

Fig. 2. Structure on college English teaching system

\section{MOOCs Resource Development on College English Teaching}

MOOCs teaching resources is the material base for class teaching mode. With the continuous development of education informationization, longed for MOOCs teaching resources research is a hotspot of current education curriculum reform, virtual learning, mobile learning and extensive in class learning represents the desire under the background of the network technology and the MOOCs integration of the new trend of the research. For MOOCs is in the informatization environment, teachers teaching video as the main form of teaching resources, students in the class 
learning resources to complete the teaching video viewing and learning, teachers and students in the classroom with complete complicated interpretation, interactive and collaborative inquiry activity. Students create a personalized collaborative teaching resources and environment is the key to MOOCs for learning. For MOOCs under the background of classroom learning environment shows rich connotation and cultural characteristics with era characteristics.

MOOCs teaching resources platform is one of the constituent parts of the information resources platform for education, combining the resources of the system management software and storage system, using computer network and communication system, through to meet user demand information processing methods and utilization of resources, to show the user the resource value of a system of information resource management platform architecture. MOOCs resource platform structure is as shown in Fig. 3.

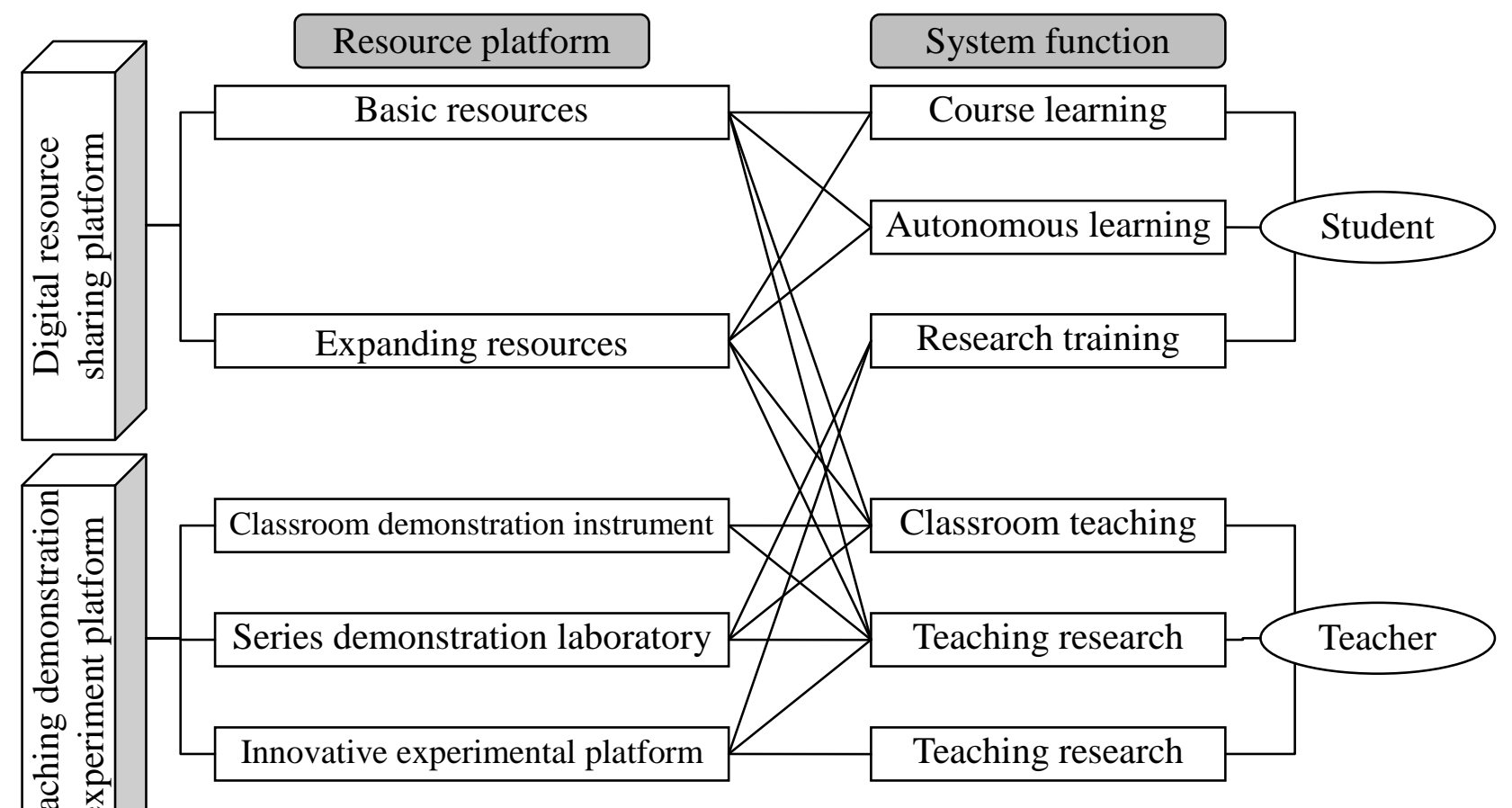

Fig. 3. Composition on MOOCs resource platform

MOOCs resources is one of the network resources, transitivity, diversity, obtain convenience to form and content richness, etc. According to the independent learning theory, from the learning objectives, learning content, learning process and learning strategies to learn the results evaluation, almost all those links to learners make a judgment, the choice and implementation, students' role from the traditional teaching of the recipient into the active explorer and participants in the learning process. Students in the process of autonomous learning are more reliance on the information resources. Main study contents in college English teaching material as the core, not only requires to master basic language knowledge, to develop a comprehensive cultural quality. So in terms of knowledge structure, expand the field of study and knowledge scope. Based on these considerations, while build in MOOCs based on the desire of college English autonomous learning environment, to ensure that provide a wealth of information resources and various forms of learning resources. A wealth of information resources will help the learners' autonomous learning. If the relevant information and learning resource unprepared, college English autonomous learning will fall into predicament $[10,11]$.

Content is very rich resources for college English teaching MOOCs, according to the source to three categories: one is that independent development of resources, including the teaching outline, electronic lesson outlines, courseware store, writings store, test paper library, awards teaching cases, etc.; Second, download the free online teaching resources, including four, six levels of thesaurus, college English vocabulary, grammar knowledge base, multimedia material library, library culture and the learning strategies and English corpus, project learning website, essays and reading material and interesting English library, etc.; Three is bought, teaching resources, including the teaching 
video and audio, database, etc. According to the content repository can be divided into listening repository, oral repository, reading, writing, repository, translation repository, lexical resource, grammatical repository, cultural resource repository, interesting English, test questions and test paper database, etc.

\section{Conclusion}

MOOCs as a technical tool, optimizes the college English teaching resources and teaching environment, teaching process and teaching goals, improve the learning and teaching efficiency, for college English teaching reform provides a new Angle of view, to introduce more worldwide topic, the introduction of effective competition mechanism, and enhances the selectivity of students learning English [12]. Practice should be based on the experience of the abroad for MOOCs teaching, try a variety of ways, from set out actually, develop a new model of college English teaching suitable for China, effectively improving the quality of English teaching, improve students' English comprehensive ability.

\section{References}

[1] D. Z. Wwng, K. Yuan, "Talking about the teaching of college English audio-visual teaching under the MOOCs environment," Journal of Huanggang Normal University, vol. 34, no. 5, pp. 153-155, 2014.

[2] L. Jin, "Research on the teaching of College English listening and speaking," China periodical network: http://www.chinaqking.com/yc/2011/149401.html, 2016-3-23.

[3] X. Y. Lian, "On the reform of College English Course under the influence of MOOCs," Journal of Fujian Medical University (Social Science Edition), vol. 15, no. 3, pp. 54-57, 2014.

[4] J. Q. Wei, "College English education from the perspective of socialization," Bridge of Century, vol. 27, no. 3, pp. 80-81, 2013.

[5] G. L. Zhang, "The transformation of teachers' role," http://www.qb5200.com/content/2016-01-27/558161.html, 2016-3-23.

[6] L. Lei, "The new idea of the development of Confucius college: the application of the teaching mode of the MOOCs," Journal of Southwest University for Nationalities (Humanities and Social Science), , vol. 36, no. 12, pp. 224-229, 2014.

[7] G. C. Su, "The systematic nature of college English teaching," China Market, vol. 13, no. 23, pp. 40-41, 2006.

[8] Y. J. Guo, "Three problems in the development of Chinese mu class," China Science Journal: http://www.qstheory.cn/kj/jyll/201404/t20140403_336890.htm, 2016-3-23.

[9] Y. Meng, "The influence of the development of Mu class on the English teaching model of Open University," Youth years, vol. 34, no. 1, pp. 90-91, 2014.

[10] Y. L. Wang, "Probe into the establishment of College English teaching resource database," Journal of Mudanjiang University, vol. 20, no. 7, pp. 152-154, 2011.

[11] M. X. Wang, "An empirical study on the optimization of College English teaching resources and the mode of talent cultivation in Local Universities," Journal of The Chinese Society of Education, vol. 36, no. S1, pp. 39-41, 2015.

[12] R. Xu, "Thinking and learning of College English MOOCs Teaching," Journal of Kaifeng Institute of Education, vol. 35, no. 6, pp. 72-73, 2015. 